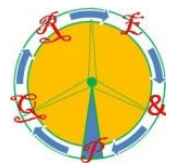

\title{
Uncertainty analysis for industries investing in energy equipment and renewable energy sources
}

\author{
E. M. Urbano ${ }^{1}$, A.D. Gonzalez-Abreu ${ }^{2}$, K. Kampouropoulos ${ }^{1}$ and L. Romeral ${ }^{1}$ \\ ${ }^{1}$ MCIA Research Center, Department of Electronic Engineering \\ Universitat Politècnica de Catalunya \\ Rambla de Sant Nebridi 2208222 Terrassa (Spain) \\ e-mail: eva.maria.urbano@upc.edu, konstantinos.kampouropoulos@upc.edu, luis.romeral@upc.edu \\ ${ }^{2}$ HSPdigital CA-Mecatronica Engineering Faculty \\ Autonomous University of Queretaro \\ San Juan del Rio 76807 Queretaro (Mexico) \\ e-mail: agonzalez63@alumnos.uaq.mx
}

\begin{abstract}
This paper studies the optimal design and operation of new energy equipment including renewable energy sources for prosumer industries. In order to augment the interest of industries in performing energy actions, the economic parameters of the investment are analysed and the risk related to it considering the uncertainty in energy markets is evaluated. A two-stage optimization approach is proposed considering the whole lifetime of the energy equipment and an uncertainty analysis performed through the evaluation of the deterministic model under Latin Hypercube Samples of uncertain parameters. A case study based on a real industry is presented, whose results expose the robustness of the optimization methodology and the acceptable risk of investing in renewable energy sources and energy equipment for prosumer purposes.
\end{abstract}

Keywords. Industry, Uncertainty Analysis, Renewable Energy, Prosumer, Net Present Value.

\section{Introduction}

The $4^{\text {th }}$ industrial revolution that is taking place is positioning this sector as key for the achievement of a sustainable energy market through the adoption of smart energy management strategies. However, the energy use in industrial enterprises is under-researched [1], and the existing studies focus primarily on energy efficiency measures [2], not studying the possibility to adopt a prosumer behaviour. In order to support industrial entities in the inclusion of renewable energy sources to behave as prosumers, the required energy investment and equipment operation problem for them should be addressed. The energy equipment design and operation optimization problems analysed in the literature until now focus on microgrids, buildings or energy hubs to supply energy to the tertiary demand. Those studies do not reflect the investment reality in the industrial sector due to two main reasons: uncertainty is not considered or time evolution is omitted.

Most of the research done up to date do not consider the uncertainty in the input parameters [3]. This approach leads to solutions that, translated into the real world with uncertain and non-deterministic parameters, may present an outcome different from the one obtained theoretically. This output uncertainty represents a risk for investors which has to be analysed. There is, in fact, a stream of research that evaluates the uncertainty in energy-related problems. In [4], the effect of the uncertainty in inputs parameter on the cost of energy is analysed for a hybrid renewable energy system. Similarly, in [5], the system behaviour uncertainty is studied, and in [6], the impact in the design parameters on the energy performance of a building is analysed. However, none of these works considers the evolution of parameters over time, and they do not evaluate the economic suitability of the energy infrastructures designed. In order to enhance industrial actors to take energy investment decisions, it is essential to study the whole expected lifetime of the energy infrastructure and analyse the uncertainty in its economic performance.

Based on the above explanation, in this paper, the uncertainty is studied for an industrial enterprise aiming to invest in energy equipment including renewable energy sources to act as a prosumer. To do so, the following analysis, as exposed in Fig. 1, is performed: 


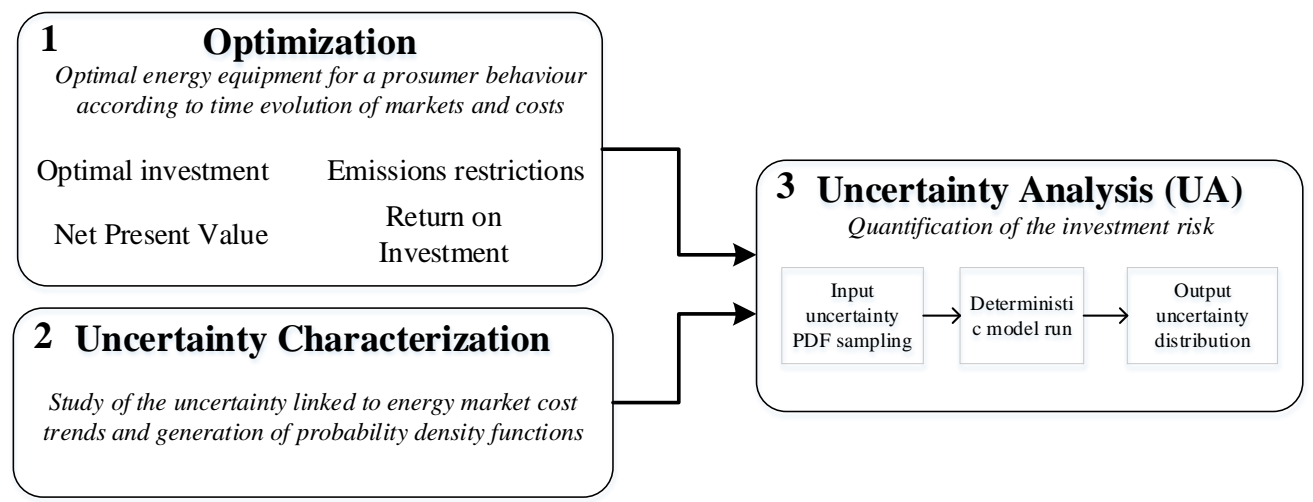

Fig. 1: Proposed methodology to assess the uncertainty in energy investment decisions

1) Design and operation optimization of the energy equipment to be installed in an industrial enterprise with prosumer behaviour considering deterministic parameters along the expected lifetime of the equipment.

2) Uncertainty characterization of the relevant input parameters.

3) Uncertainty Analysis (UA) of the energy investment Net Present Value (NPV) to quantify the risk related to the investment decision.

This paper is structured as follows. Firstly, the methodology applied to perform the optimization of the investment is presented in section 2 together with the uncertain inputs' characterization and the UA strategy. Then, in section 3, this methodology is applied to a case study reflecting the real industrial situation. The results of this case study and their discussion are exposed in section 4 and, lastly, the conclusions of the study are presented in section 5 .

\section{Methodology}

In this section, the methodology proposed to properly optimize the energy equipment and its operation considering the whole lifetime framework and assess the relevant uncertainties linked to its performance is exposed. The general workflow for the approach presented is shown in Fig. 1. First of all, the optimization of the energy infrastructure is performed considering the input parameters as deterministic along the expected lifetime of the equipment, which is taken to be 15 years. Then, the uncertain inputs are identified and their probability distributions characterized to be able to evaluate their influence on the output. Finally, the uncertainty in the economic performance of the decision is studied through a UA.

\section{A. Optimization of the energy equipment}

Considering industrial enterprises interest, the optimization of the energy equipment aims to maximize the final economic value of the energy infrastructure to install. In order to do so, a two-stage optimization approach is presented to maximize the NPV of the investment. The two-stage optimization strategy enables to obtain the design parameters in the first stage, formed by the equipment to install and their sizes while considering their operation in the second-stage. The flowchart of the approach can be seen in Fig. 2 .

First of all, information is gathered and the data required to perform the optimization along the lifetime of the equipment is computed. To capture the yearly behaviour of the plant along its lifetime with a feasible computational expense, a set of typical days are employed. According to $[7,8]$, these days have to be distributed per season to correctly represent the different types of demands that occur along the year, being suitable the use of one day per season or one day per month. However, the industrial sector and the electricity market also present significative energy differences between week-days and weekend-days, requiring their consideration for the selection of typical days. Thus, for the problem under study, each of the years is analysed through 12 characteristic days, three per season, being two of them week-days and the other a weekend-day.

In order to obtain the NPV of the investment, it is required to obtain its benefits compared to a baseline scenario. For this reason, a linear optimization of the baseline of the enterprise, with the current existent energy infrastructure, is performed. Then, the first stage of the optimization is initialized. For the problem under study here, the Direct Search (DS) optimizer is employed due to its capability to globally search the optimal value in an efficient manner for a limited set of variables with clearly defined boundaries. DS selects a set of candidates, which are evaluated in the second stage and their NPV computed. In the second stage, the operation of the energy infrastructure selected as candidates is evaluated for the whole lifetime through a Linear Programming (LP) approach, assuring the achievement of minimal costs. The restrictions regarding emissions and payback are verified and, if accomplished, the NPV of the investment is computed comparing the operation of the upgraded plant with that of the baseline. This procedure is repeated until the first-stage optimizer reaches an optimal value. 


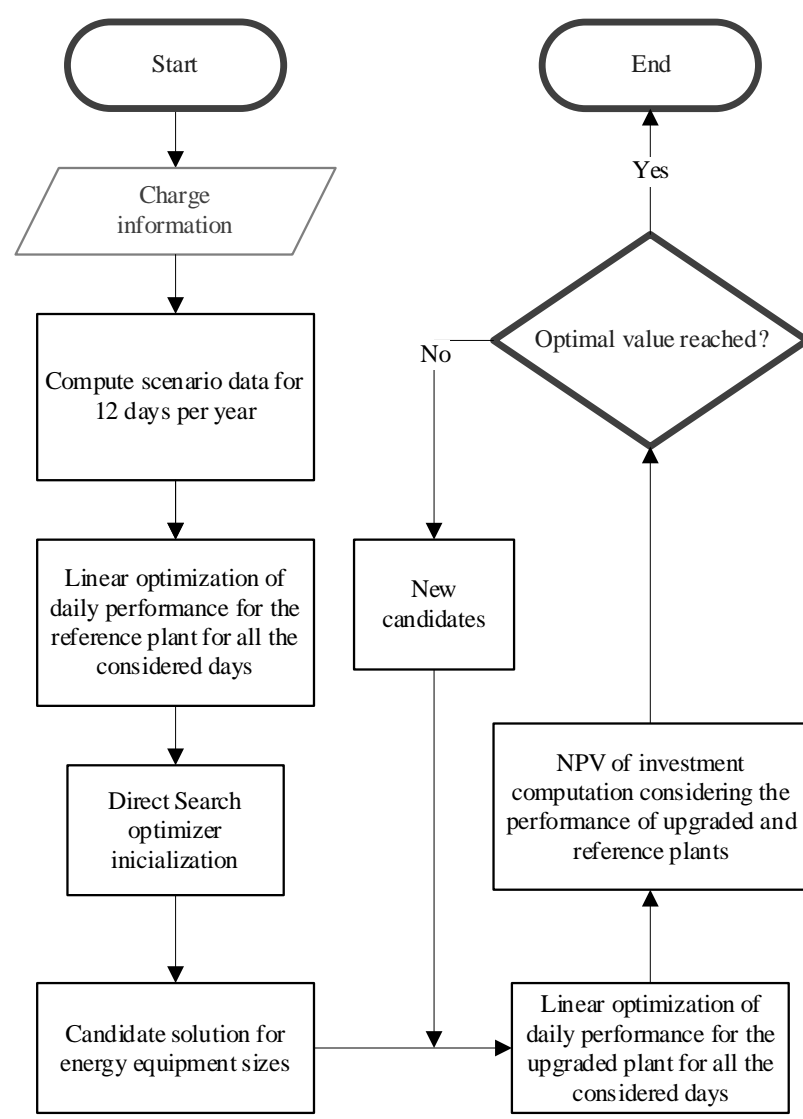

Fig. 2: Flowchart for the energy design optimization

\section{B. Uncertainty characterization}

The energy infrastructure of the industry as a prosumer has a performance linked to the costs of the energy carriers. As the energy transition will affect the energy markets and the cost of energy is forecasted to grow continuously in upcoming years, although at different rates depending on the forecasting approach adopted [9], it is essential to study how this evolution and its uncertainty affect the result of the investment performed by the industry.

These uncertain parameters are considered by assigning a Probability Distribution Function (PDF) to each of them, which enables the application of methods that consider the probability of the occurrence of scenarios and provides robust results [10]. According to $[9,11,12]$, the cost of electricity is forecasted to increase between $25 \%$ and $110 \%$ by 2035 ; while the cost of gas is forecasted to increase between $11 \%$ and $33 \%$ [9,13]. These yearly percentage values are transformed into PDF fitting possible distribution functions and selecting the most suitable ones as evaluated by the likelihood function. The resultant distributions functions are exposed in Table I.

Table I: PDF of the studied uncertain inputs

\begin{tabular}{|l|c|}
\hline \multicolumn{1}{|c|}{ Uncertain parameter } & PDF \\
\hline $\begin{array}{l}\text { Electricity price yearly percentage } \\
\text { increase }\end{array}$ & $\begin{array}{c}\text { Nakagami }(\mu=0.885 ; \\
\omega=10.14)\end{array}$ \\
\hline $\begin{array}{l}\text { Gas price yearly percentage } \\
\text { increase }\end{array}$ & $\begin{array}{c}\text { Weibull } \\
(\lambda=1.44 ; k=3,11)\end{array}$ \\
\hline
\end{tabular}

\section{Uncertainty Analysis}

Once the optimal design and operation of the plant is obtained and the uncertainty in the inputs is characterized, it is possible to perform a UA to evaluate the uncertainty in the output of the system which, in this case, is the NPV of the investment.

A UA method that considers the PDFs of inputs to obtain the distribution in the output through sampling and repeatedly evaluating the deterministic model is a suitable strategy that provides robust results [14]. In this case, and given the complexity of the system, a quasirandom sampling strategy is selected. This type of strategy improves the performance of commonly used techniques such as Monte Carlo [15], which requires a high computational effort. In this paper, the Latin Hypercube Sampling (LHS) technique is used [16]. LHS is a probabilistic technique that obtains samples by dividing the PDF into $N$ intervals with equal probability and choosing randomly one sample per interval. Combining randomly the different samples, $N$ scenarios are generated which are used to run $N$ times the deterministic model, enabling to capture the uncertainty in the output.

\section{Case study}

A case study is developed based on a real manufacturing industrial plant with total electrical and thermal consumptions of 679,240 MWh and 1,127,600 MWh, respectively. The initial infrastructure of the plant consists of a boiler to transform natural gas into thermal energy, while the electrical demand is directly met with energy purchased at the utility grid. The enterprise is considering the possibility to install a PV system as well as cogeneration and energy storages. To account for the deterioration of the PV system along its expected lifetime, an efficiency loss of $0.8 \%$ per year has been considered [17]. The capital cost and the levelized cost of energy (LCOE) including operation and maintenance costs employed in the optimization process for each of the evaluated technologies can be seen in Table II.

Table II: Cost of energy equipment

\begin{tabular}{|l|c|c|}
\hline \multicolumn{1}{|c|}{ Equipment } & Capital cost & LCOE \\
\hline PV system & $950 € / \mathrm{kW}$ & $0.07 € / \mathrm{kWh}$ \\
\hline CHP & $3,400 € / \mathrm{kWe}$ & $0.042 € / \mathrm{kWh}$ \\
\hline Electrochemical energy storage & $430 € / \mathrm{kWh}$ & $0.06 € / \mathrm{kWh}$ \\
\hline
\end{tabular}

The constraints considered by the studied enterprise regarding the investment and its performance are exposed in Table III.

Table III: Applicable constraints for the case study

\begin{tabular}{|l|c|}
\hline \multicolumn{1}{|c|}{ Constraint } & $\begin{array}{c}\text { Value for the case } \\
\text { study }\end{array}$ \\
\hline Maximum investment & $1,000,000 €$ \\
\hline $\begin{array}{l}\text { Maximum area for the installation of } \\
\text { PV }\end{array}$ & $12,000 \mathrm{~m}^{2}$ \\
\hline
\end{tabular}




\section{Results and discussion}

\section{A. Deterministic optimization}

The optimal energy infrastructure to install is exposed in Table IV. The PV system is chosen to cover all the available space and the cogeneration is sized to optimally fulfil demand and interact with the utility grid obtaining the maximum profit. It can be seen that although there was the possibility to include energy storage, this has not been selected due to its high cost compared with the possible revenue obtained by trading its energy with the utility grid. The decision to upgrade the energy infrastructure with this equipment supposes an investment of $913,630 €$ with a payback period of 5 years and an NPV at the end of the lifetime of the equipment of $6,788,400 €$.

Table IV: Optimal energy equipment to install in the industrial case study

\begin{tabular}{|l|c|}
\hline Energy equipment selected & Size \\
\hline PA Area & $12,000 \mathrm{~m}^{2}$ \\
\hline Cogeneration & $200 \mathrm{We}$ \\
\hline
\end{tabular}

The prosumer behaviour of the plant for a typical autumn week-day and a typical autumn weekend-day can be seen in Fig. 3 and Fig. 4, where the energy exchange with the utility grid is exposed in front of the energy cost at the wholesale market and the internal electrical demand. It is possible to see that, due to the existence of a renewable energy source, surplus energy can be injected into the utility grid when the cost is high while still fulfilling internal demand. Also, and due to the difference in costs between the electrical and gas energy carriers, the inclusion of a cogeneration system is favourable to support fulfilling electrical demand and thus not purchasing it directly from the electrical grid at high costs.

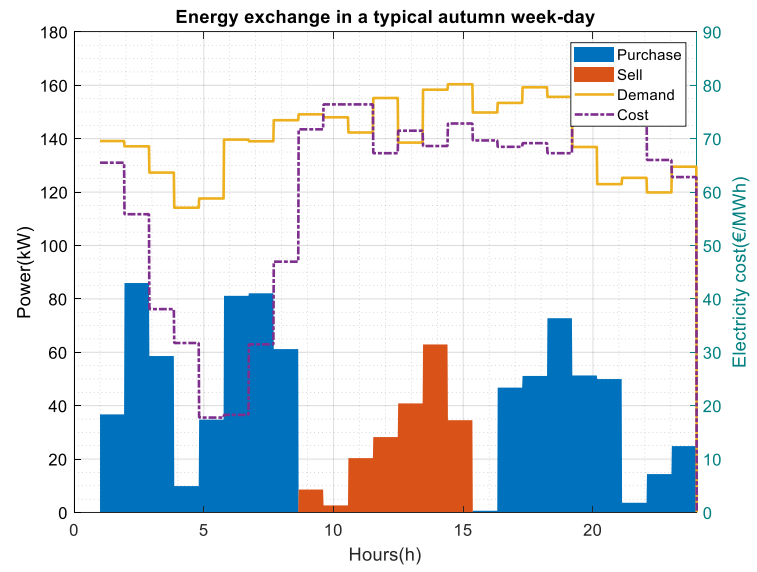

Fig. 3: Prosumer energy exchange for an autumn weekday

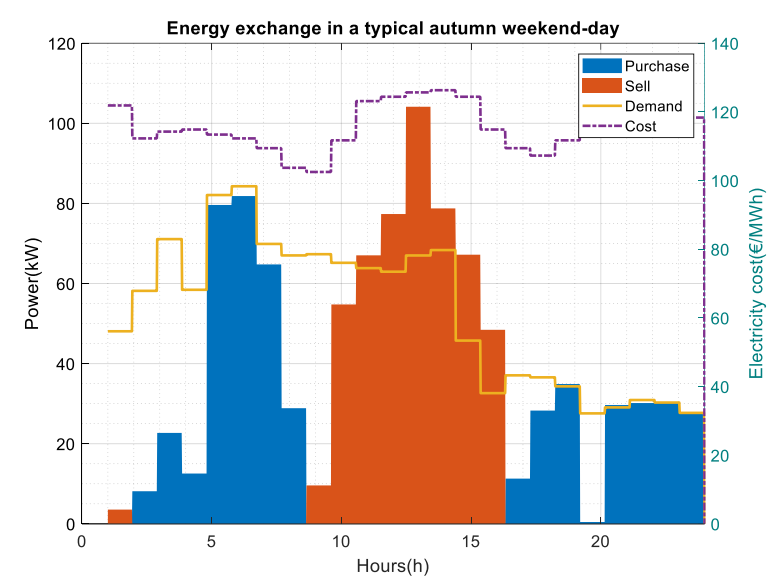

Fig. 4: Prosumer energy exchange for an autumn weekend

\section{B. Uncertainty Analysis}

Once the deterministic behaviour is obtained, in this section the results for the UA are exposed to evaluate the risk of performing the energy investment and the optimal operation selected in the previous stage. To perform the UA, the PDFs of the electricity and gas costs are sampled for each of the years to obtain realistic time evolution scenarios. A total number of 1000 is generated, which is a suitable value to obtain an accurate and representative result [6]. These samples are then randomly combined between them, creating the scenarios analysed, which are employed to repeatedly run the deterministic plant model, obtaining the final NPV distribution, which is exposed in Fig. 5.

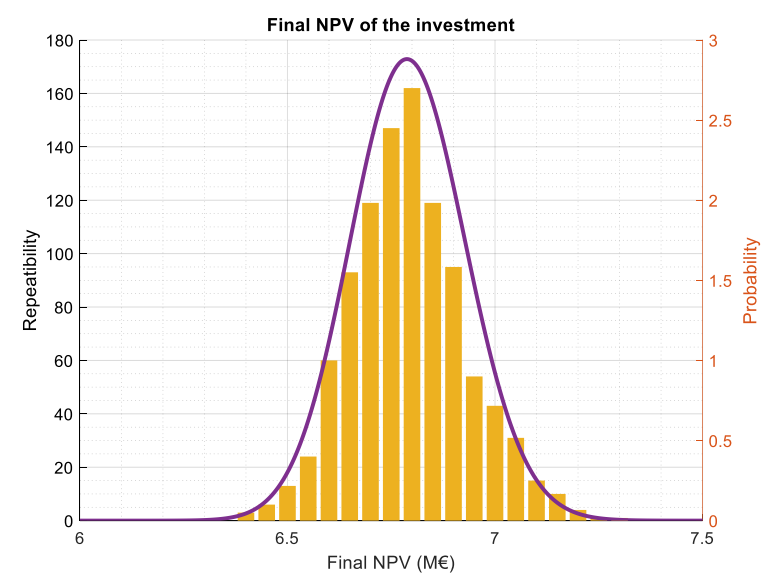

Fig. 5: Probability distribution of the NPV according to inputs' uncertainties

In this figure, it is possible to appreciate the repeatability of the obtained NPV as well as the PDF that best fits the data, which in this case is an Inverse Gaussian with parameters $(\mu=6.792 ; \lambda=16,324)$. The standard deviation of the NPV is $138,500 €$, which means that it is probable to have a final NPV $138,500 €$ lower or higher than the obtained in a deterministic manner due to the uncertainties in the energy markets. Although the standard deviation is by itself a considerable amount, the final deterministic NPV is $6,788,400 €$, meaning that this value can vary due to the uncertainty present in the energy markets a $2 \%$. 
These results clarify the impact of energy market uncertainties in energy investment. With the obtained values in this case study, it is shown that despite the expected variations in the cost of energy carriers, the economic value for energy infrastructures adopting a prosumer behaviour is robust and the risk can be acceptable by enterprises.

\section{Conclusions}

The economic benefits of including renewable energy sources and new transformer equipment to adopt prosumer behaviour have been analysed in this paper. A workflow to study the energy investment characteristics and their uncertainties has been presented, including the optimal design and operation, the characterization of uncertainties of energy carrier prices, and the Uncertainty Analysis, performed through repeatedly evaluating the model under the uncertain scenarios obtained through Latin Hypercube Sampling. This methodology has been applied to a case study that represents a typical industry with electrical and thermal demand and the capability to install a PV system and transformer and storage equipment. For this case study, it is optimal to install the PV system in all the available space and incorporate a cogeneration system to link the electrical and thermal sides of the industry. The Net Present Value (NPV) of the investment multiplies by more than 7 the initial investment required and the payback period is of 5 years, making energy infrastructure upgrading an interesting option for industrial enterprises. This energy investment decision has been analysed under the uncertainty present in the energy markets, represented by the increase in the cost of energy carriers. With current uncertain values, the expectable NPV of the investment varies $2 \%$ concerning its deterministic value, showing the robustness of the optimization procedure. These results are of high utility for the industrial sector, enhancing them to perform energy actions and providing a framework for industrial enterprises to evaluate their energy investment decisions.

\section{Acknowledgement}

This research has been funded by European Social Fund, the Secretariat of Universities and Research of Catalonia, the Generalitat de Catalunya under the grant number 2017 SGR 967 and partly co-financed by the European Regional Development Fund of the European Union in the framework of the ERDF Operational Program of Catalonia 2014-2020 under the Research Project 001-P-001722 Agrupació emergent Looming Factory.

\section{References}

[1] Fawcett T, Hampton S. Why \& how energy efficiency policy should address SMEs. Energy Policy 2020; $140: 111337$. https://doi.org/10.1016/j.enpol.2020.111337.

[2] König W, Löbbe S, Büttner S, Schneider C. Establishing Energy Efficiency-Drivers for Energy Efficiency in German Manufacturing Small-and-Medium-Sized Enterprises. Energies 2020.

[3] Anoune K, Bouya M, Astito A, Abdellah A Ben. Sizing methods and optimization techniques for PV-wind based hybrid renewable energy system: A review. Renew
Sustain Energy Rev 2018;93:652-73.

https://doi.org/10.1016/j.rser.2018.05.032.

[4] Sanajaoba Singh S, Fernandez E. Modeling, size optimization and sensitivity analysis of a remote hybrid renewable energy system. Energy 2018;143:719-31.

https://doi.org/10.1016/j.energy.2017.11.053.

[5] Fodhil F, Hamidat A, Nadjemi O. Potential, optimization and sensitivity analysis of photovoltaicdiesel-battery hybrid energy system for rural electrification in Algeria. Energy 2019;169:613-24. https://doi.org/10.1016/j.energy.2018.12.049.

[6] Li H, Wang S, Cheung H. Sensitivity analysis of design parameters and optimal design for zero/low energy buildings in subtropical regions. Appl Energy 2018;228:1280-91.

https://doi.org/10.1016/j.apenergy.2018.07.023.

[7] Renedo CJ, Ortiz A, Mañana M, Silió D, Pérez S. Study of different cogeneration alternatives for a Spanish hospital center. Energy Build 2006;38:48490. https://doi.org/10.1016/j.enbuild.2005.08.011.

[8] Seo H, Sung J, Oh SD, Oh H suk, Kwak HY. Economic optimization of a cogeneration system for apartment houses in Korea. Energy Build 2008;40:961-7.

https://doi.org/10.1016/j.enbuild.2007.08.002.

[9] Perez-Linkenheil C. EU Energy Outlook 2050. Energy BrainPool GmbH CoKG 2019.

https://blog.energybrainpool.com/en/update-december2019-eu-energy-outlook-2050/ (accessed December 9, 2020).

[10] Delgarm N, Sajadi B, Azarbad K, Delgarm S.

Sensitivity analysis of building energy performance: A simulation-based approach using OFAT and variancebased sensitivity analysis methods. J Build Eng 2018;15:181-93.

https://doi.org/10.1016/j.jobe.2017.11.020.

[11] European Commission. Report from the commission to the European Parliament, the Council, The European Economic and Social Committee and the Committee of the regions: Energy prices and costs in Europe. COM(2019) 2019.

[12] Mavromatidis G, Orehounig K, Carmeliet J. Uncertainty and global sensitivity analysis for the optimal design of distributed energy systems. Appl Energy 2018;214:219-38.

https://doi.org/10.1016/j.apenergy.2018.01.062.

[13] Zhou F, Page L, Perrons RK, Zheng Z, Washington S. Long-term forecasts for energy commodities price: What the experts think. Energy Econ 2019;84:104484. https://doi.org/10.1016/j.eneco.2019.104484.

[14] Tran TTD, Smith AD. Incorporating performancebased global sensitivity and uncertainty analysis into LCOE calculations for emerging renewable energy technologies. Appl Energy 2018;216:157-71. https://doi.org/10.1016/j.apenergy.2018.02.024.

[15] Tian W, Heo Y, de Wilde P, Li Z, Yan D, Park CS, et al. A review of uncertainty analysis in building energy assessment. Renew Sustain Energy Rev 2018;93:285301. https://doi.org/10.1016/j.rser.2018.05.029.

[16] Helton JC, Johnson JD, Sallaberry CJ, Storlie CB. Survey of sampling-based methods for uncertainty and sensitivity analysis. Reliab Eng Syst Saf 2006;91:1175-209. https://doi.org/10.1016/j.ress.2005.11.017.

[17] Jordan DC, Sekulic B, Marion B, Kurtz SR. Performance and Aging of a 20-Year-Old Silicon PV System. IEEE J Photovoltaics 2015;5:744-51. https://doi.org/10.1109/JPHOTOV.2015.2396360. 